\title{
PENGARUH LATIHAN SMALL SIDED GAMES TERHADAP PENINGKATAN AKURASI PASSING PADA SISWA SSB BINA TARUNA TAMBAKROMO PATI
}

\author{
Ahmad Badawi ${ }^{1^{*}}$, Ibnu Fatkhu Royana ${ }^{2}$, Maftukin Hudah ${ }^{3}$ \\ ${ }^{1}$ Pendidikan Jasmani Kesehatan dan Rekreasi, Universitas PGRI Semarang, Semarang, Indonesia \\ ${ }^{2}$ Pendidikan Jasmani Kesehatan dan Rekreasi, Universitas PGRI Semarang, Semarang, Indonesia \\ ${ }^{3}$ Pendidikan Jasmani Kesehatan dan Rekreasi, Universitas PGRI Semarang, Semarang, Indonesia \\ *badawiahmad904@gmail.com
}

(Received: September 2019 / Revised: November 2019 / Accepted: November 2019)

\begin{abstract}
ABSTRAK: Small sides games merupakan salah satu bentuk latihan sepak bola yang memungkinkan pemain untuk melakukan lebih banyak passing. Penelitian ini bertujuan untuk mengetahui pengaruh latihan small sided games terhadap peningkatan akurasi passing siswa SSB Bina Taruna Tambakromo Pati. Penelitian ini merupakan penelitian eksperimen dengan desain penelitian one group pretest-posttest design. Populasi dalam penelitian ini adalah siswa SSB Bina Taruna Tambakromo yang berusia 14 tahun dengan jumlah 30 siswa. Sampel dalam penelitian ini menggunakan teknik purposive sampling dengan jumlah 20 siswa. Intsrumen yang digunakan dalam penelitian ini adalah tes mengoper bola rendah yang disusun oleh Subagyo Irianto dalam abdul karim dengan tingkat validitas sebesar 0,653 dan tingkat reabilitas sebesar 0,879 . Teknik analisis data menggunakan uji-t melalui uji prasyarat uji normalitas dan uji homogenitas. Hasil penelitian yang diperoleh nilai $\mathrm{t}$ hitung $>\mathrm{t}$ tabel $(4,74>1,73)$, hasil ini menunjukkan bahwa terdapat pengaruh yang signifikan dari latihan small sides games terhadap peningkatan akurasi passing siswa SSB Bina Taruna Tambakromo. Berdasarkan perbedaan hasil rata-rata (mean difference) dari pre-test dan posttest maka dapat diketahui besarnya persentase peningkatan akurasi passing siswa SSB Bina Taruna Tambakromo sebesar 38,61\%.

KATA KUNCI: $\quad$ Small Sided Games, Akurasi Passing, Sepak Bola.

ABSTRACTS: Small Sides Games is a form of soccer practice that allows players to do more passes. This study aims to determine the effect of small sided games exercises on increasing the passing accuracy of SSB Bina Taruna Tambakromo Pati students. This research is an experimental study with one group pretestposttest design research design. The population in this study were 14 years old SSB Bina Taruna Tambakromo students with 30 students. The sample in this study used a purposive sampling technique with a total of 20 students. The instrument used in this study was a low ball pass test prepared by Subagyo Irianto in abdul karim with a validity level of 0.653 and a reliability level of 0.879 . The data analysis technique used t-test through the prerequisite test for normality test and homogeneity test. The results obtained by the value of $t$ arithmetic $t$ table (4.74> 1.73), these results indicate a significant effect of the small sides games exercise on increasing the passing accuracy of students of Bina Taruna Tambakromo SSB. Based on the difference in the mean results (mean difference) of the pre-test and post-test, it can be seen the percentage increase in the passing accuracy of students of Bina Taruna Tambakromo by $38.61 \%$.

KEYWORD: Small Sided Games, Passing Accuracy, Footbal.
\end{abstract}

\section{PENDAHULUAN}

Olahraga Sepak Bola merupakan salah satu cabang olahraga yang paling banyak diminati penduduk dunia, tidak terkecuali di Indonessia. Cabang olahraga ini dimainkan 2 tim yang masing- masing timya berisi 11 pemain inti. olahraga ini dimainkan di sebuah lapangan berumpput yang sangat luas. Olahraga ini berkembang menjadi sangat popular seiring dengan semakin berkembangnya dunia olahraga.olahraga sepak bola sendiri memiliki tujuan, yaitu meraih 
kemenangan dengan mencetak gol sebanyak mungkin ke gawang lawan dan menjaga agar tidaak kemasukan gol dari tim lawan. (Rahmani, 2014).

Untuk dapat bermain sepak bola harus menguasai teknik- teknik dasar sepak bola yang baik. Untuk dapat menghasilkan permainan sepak bola yang optimal, maka seorang pemain harus dapat menguasai teknik-teknik dalam permainan. Adapun teknik dasar sepak bola ada 2 yaitu, Teknik tanpa bola yaitu semua gerakan-gerakan tanpa bola meliputi : lari cepat dengan mengubah arah, melompat dan meloncat, gerakan tipu dengan badan, serta gerakan khusus penjaga gawang. Sedangkan teknik dengan bola meliputi : mengenal bola (ball feeling), mengoper bola (passing), menerima dan menguasai bola (receiveing and controlling the ball), menggiring bola (dribbling), menyundul bola (heading), menendang bola (shooting), melempar bola (throwing, merebut bola (sliding tackle-sliding), dan menjaga gawang (goal keeping). (Herdiansyah \& Nurasyifa, 2010).

Passing dalam permainan sepak bola memiliki tujuan yaitu mengoper bola pada teman satu tim agar dapat menciptakan ruang, sehingga pemain dapat menciptakan gol ke gawang lawan dan dapat mempertahankan daerah pertahanan bagi pemain bertahan agar tidak kemasukan gol.Teknik dalam melakukan passing dibedakan menjadi 3 yaitu; 1) Passing dengan kaki bagian dalam, 2) Passing dengan kaki bagian luar, 3) Passing dengan punggung kaki. Latihan small sided games adalah salah satu bentuk latihan yang memodifikasi permainan sepakbola dengan adanya pembatasan, meliputi pembatasan jumlah pemain, ukuran lapangan, dan lama permainan. Permainan penguasaan bola (possession) dan lapangan yang lebih kecil (small sided games) dengan lebih sedikit pemain sangat baik untuk menumbuhkan pengertian taktis sekaligus mengasah kemampuan teknis pemain (Scheunemann, 2012: 4).

SSB Bina Taruna merupakan salah satu perkumpulan atau organisasi sepak bola yang berkembang di Kabupaten Pati. Sekolah Sepak bola Bina Taruna Tambakromo Pati berdiri pada tahun 2010 yang beralamatkan di Dusun Koripan, Desa Mojomulyo Kecamatan Tambakromo Kabupaten Pati. SSB Bina Taruna terbentuk karena adanya keinginan untuk turut berpartisipasi dalam mengembangkan bakat-bakat muda dalam olahraga sepak bola. Prestasi yang pernah dicapai oleh SSB Bina Taruna bisa dibilang cukup bagus, yaitu pada tahun 2012 pernah manjadi juara 2 dalam turnamen sepakbola U-14 tingkat jawa tengah, dan tahun 2013 masuk menjadi juara 1 piala Bupati Pati.

Dari hasil observasi dan wancara dengan pelatih SSB yang dilakukan peneliti, peneliti menemukan masalah tingkat akurasi passing yang dimiliki siswa kurang baik, dan dari hasil wawancara dengan pelatih bapak selamet riyadi menyatakan "tingkat akurasi passing kurang baik siswa bisa dilihat saat sesi latihan dengan menggunakan lapangan penuh banyak passingpassing yang tidak akurat dan sering menyulitkan teman satu tim untuk menguasai bola". dalam program latihan pelatih menerapkan latihan passing berpasangan dan kucing-kucingan bertujuan untuk meningkatkan akurasi passing siswa SSB Bina Taruna.

Dari hasil Tes passing bola rendah berjarak 18 meter dengan gawang ditempatkan ditengahtengah sebagai bidang sasaran yang peneliti lakukan pada tanggal 4 Oktober 2018 pada 20 siswa SSB Bina Taruna Tambakromo dengan 10 kali percobaan melakukan passing hanya ada 1 anak yang akurasi passing baik dengan 8 kali passing tepat pada sasaran. Sedangkan 19 siswa lainya dari 10 kali percobaan akurasi passing yang tepat pada sasaran kurang dari 7 kali passing tepat 
pada sasaran. Dengan kondisi diatas, peneliti berasumsi perlu adanya variasi latihan yang baru untuk meningkatkaan akurasi passing siswa SSB Bina Taruna. peneliti ingin menerapkan variasi latihan akurasi passing siswa dengan model latihan small sided game.

\section{METODE PENELITIAN}

Penelitian ini termasuk pra-eksperimen. Metode eksperimen didefinisikan sebagai metode sistematis guna membangun hubungan yang mengandung fenomena sebab akibat (Causaleffect relationship) (Sukardi, 2015: 178). Desain yang digunakan dalam penelitian ini adalah "The One Group Pretest Posttest Design" atau tidak adanya grup kontrol (Sukardi, 2015: 184). Penelitian ini akan membandingkan pretest dan posttest akurasi passing siswa SSB Bina Taruna Tambakromo Adapun rancangan tersebut sebagai berikut:

Tabel 1. Desain Penelitian

\begin{tabular}{ccc}
\hline Pretest & Variable Terikat & Posttest \\
\hline $\mathrm{Y} 1$ & $\mathrm{X}$ & $\mathrm{Y} 2$ \\
\hline
\end{tabular}

Keterangan:

Y1: Pengukuran Awal (Pretest)

$X:$ Perlakuan (Treatment)

Y2: Pengukuran Akhir (Posttest)

Menurut Arikunto (2010: 134) instrumen penelitian adalah alat bantu yang digunakan dan dipilih peneliti dalam kegiatannya mengumpulkan agar kegiatan tersebut menjadi sistematis dan dipermudah. Instrumen tes yang digunakan untuk pengukuran awal (pretest) maupun pengukuran akhir (posttest) menggunakan tes keterampilan bermain sepakbola yang disusun oleh Irianto (1995) dalam Abdul Karim (2018).

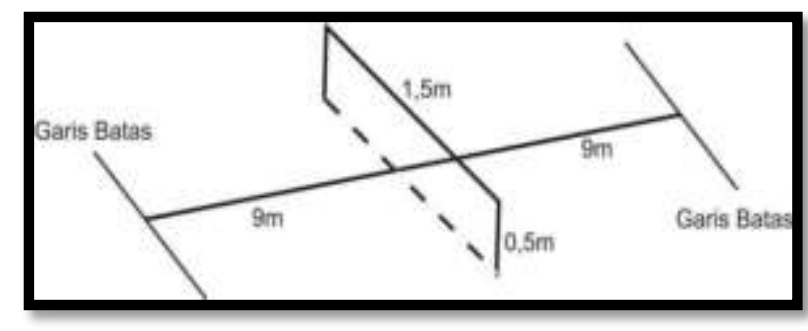

Gambar 1. Test mengoper bola rendah

Alat yang digunakan untuk tes mengoper bola rendah yaitu; 1)Bola, 2)Lapangan datar, 3)Meteran, 4)Gawang kecil ukuran panjang 1,5 m dan tinggi $0,5 \mathrm{~m}$. Tempat dan gawang dipersiapkan sebelum pelaksanaan tes sehingga tidak mengganggu dalam pelaksanaan tes mengoper bola rendah. Validitas tes tersebut adalah 0,653 dan reliabilitas sebesar 0,879. Passing dikatakan tepat apabila masuk pada sasaran yang telah ditentukan melewati garis sah yang telah ditentukan.

Sebelum dilakukan pengujian hipotesis, maka perlu dilakukan uji prasyarat. Pengujian terhadap hasil pengukuran yang berhubungan dengan hasil penelitian bertujuan untuk membantu analisis agar menjadi lebih baik. Untuk itu dalam penelitian ini akan di uji normalitas dan uji homogenitas data.

Uji Normalitas sampel atau menguji normal tidaknya sampel, tidak lain sebenarnya adalah mengadakan pengujian terhadap normal tidaknya sebaran data yang akan dianalisis. Pengujian dilakukan tergantung variabel yang akan diolah. Pengujian normalitas sebaran data menggunakan Kolmogorov-Smirnov dengan bantuan program SPSS 17. Kaidah normalitas jika sig $<0.05$ maka sebaran data dinyatakan tidak normal, jika sig > 0.05 maka sebaran data dinyatakan normal.

Selain pengujian terhadap penyebaran nilai yang akan di analisis, perlu uji homogenitas agar yakin bahwa kelompok-kelompok yang membentuk sampel berasal dari populasi yang sama dengan menggunakan bantuan program SPSS 17. Kaidah homogenitas jika $p>0.05$, maka 
Journal of Sport and Exercise Science, Vol 2, No 2, 2019 (60-65)

Pengaruh Latihan Small Sided Games terhadap Peningkatan Akurasi PASSING pada Siswa SSB Bina Taruna Tambakromo Pati

data dinyatakan homogen, jika $\mathrm{p}<0.05$, maka data dikatakan tidak homogen.

Pengujian hipotesis menggunakan uji-t dengan menggunakan bantuan program SPSS 17 yaitu dengan membandingkan mean antara hasil pre-test dengan hasil post-test. Apabila nilai $\mathrm{t}$ hitung lebih kecil dari t tabel maka Ho ditolak, jika $\mathrm{t}$ hitung lebih besar dari $\mathrm{t}$ tabel maka Ho diterima. Taraf signifikan sebesar 0,05.

\section{HASIL}

Penelitian ini dilaksanakan pada tanggal 7 Maret 2019 sampai 11 April 2019 yang dilakukan di lapangan Desa Mojomulyo Kecamatan Tambakromo. Peneliti menggunakan 20 sampel siswa SSB Bina Taruna. Data penelitian yang diperoleh berasal dari data pretest dan data posttest yang dilakukan oleh seluruh siswa SSB Bina Taruna Tambakromo. Deskripsi data akan menyajikan nilai maksimum, nilai minimum, ratarata, standar deviasi.

Hasil analisis statistik deskriptif pretest dan posttest tingkat akurasi passing siswa SSB Bina Taruna Tambakromo usia 14 tahun, disajikan pada tabel di bawah ini:

Tabel 1. Deskriptif Statistik Pretest dan Posttet

\begin{tabular}{ccc}
\hline Statistik & Pretest & Posttest \\
\hline $\mathrm{N}$ & 20 & 20 \\
\hline Mean & 5,45 & 7,50 \\
\hline Range & 6,00 & 4,00 \\
\hline Std. Deviation & 1,605 & 1,277 \\
\hline Minimum & 3,00 & 5,00 \\
\hline Maksimum & 9,00 & 9,00 \\
\hline Sum & 109 & 150 \\
\hline
\end{tabular}

Histogram deskriptif statistik pretest dan posttest siswa SSB Bina Taruna Tambakromo .

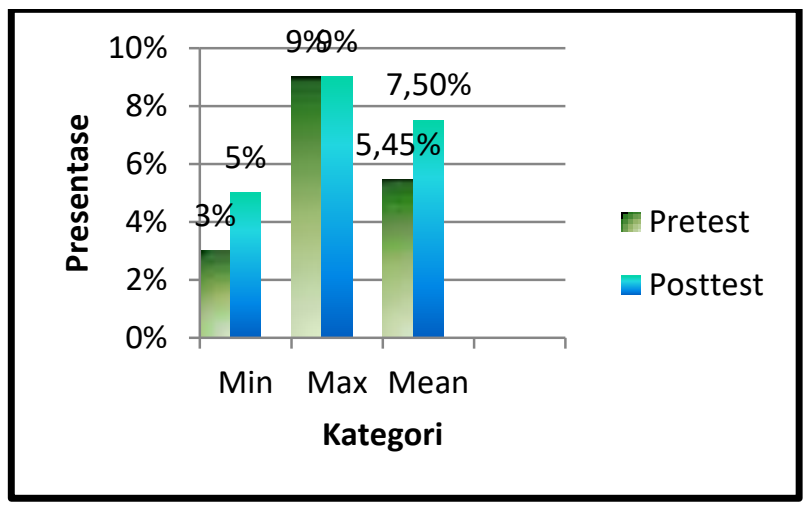

Grafik 1. Histogram desktiptif Pretest dan Posttest

Siswa SSB Bina Taruna Tambakromo berdasarkan histogram diatas dari hasil penelitian pretest sebelum diberikan perlakuan /treartment nilai minimum 3,00, maksimum 9,00 dan mean 5,45 . Sedangkan hasil penelitian posttest setelah diberi perlakuan/treartment memperoleh nilai minimum 5,00 , nilai maksimum 9,00 dan mean 7,50. Apabila ditampilkan dalam bentuk distribusi frekuensi, hasil pretest dan posttest akurasi passing siswa SSB Bina Taruna Tambakromo yang berusia 13-14 tahun disajikan pada tabel 7 sebagai berikut:

Tabel 3. Distribusi Frekuensi Pretest dan Posttest Akurasi Passing

\begin{tabular}{ccccccc}
\hline \multirow{2}{*}{ No } & \multirow{2}{*}{ Skor } & \multirow{2}{*}{ Kategori } & \multicolumn{2}{c}{ Pretest } & \multicolumn{2}{c}{ Posttest } \\
\cline { 3 - 7 } 1 & $9-10$ & $\begin{array}{c}\text { Sangat } \\
\text { Baik }\end{array}$ & 1 & $5 \%$ & 6 & $30 \%$ \\
\hline 2 & $7-8$ & Baik & 3 & $15 \%$ & 9 & $45 \%$ \\
\hline 3 & $5-6$ & Sedang & 11 & $55 \%$ & 5 & $25 \%$ \\
\hline 4 & $3-4$ & Rendah & 5 & $20 \%$ & 0 & $0 \%$ \\
\hline 5 & $0-2$ & $\begin{array}{c}\text { Sangat } \\
\text { Rendah }\end{array}$ & 0 & $0 \%$ & 0 & $0 \%$ \\
\hline \multicolumn{3}{c}{ Jumlah } & & $100 \%$ & & $100 \%$ \\
\hline
\end{tabular}

Berdasarkan distribusi frekuensi pada tabel 7 tersebut di atas, hasil pretest dan posttest akurasi passing siswa SSB Bina Taruna Tambakromo yang berusia 13-14 tahun dapat disajikan pada gambar sebagai berikut: 


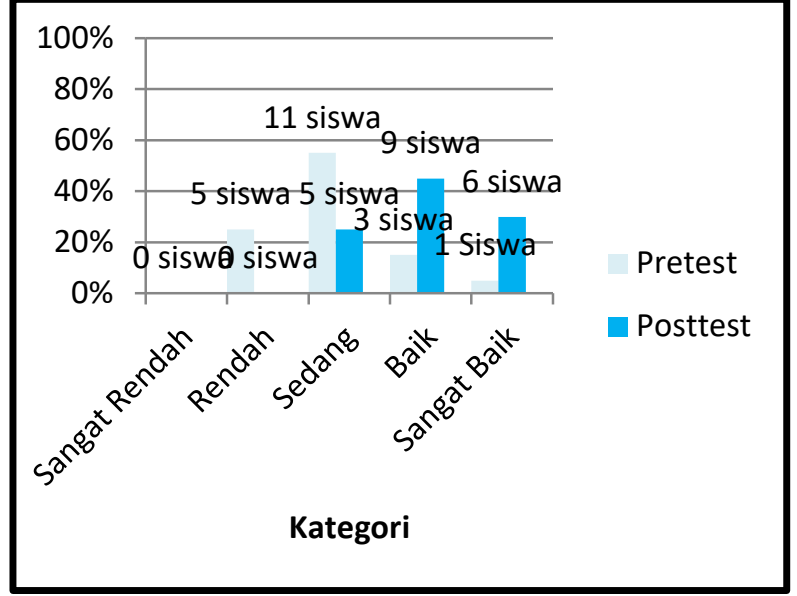

Grafik 2. Histogram Pretest dan Posttest akurasi passing

Berdasarkan histogram di atas menunjukkan bahwa hasil pretest dan posttest akurasi passing siswa SSB Bina Taruna Tambakromo, untuk hasil pretest berada pada kategori "sangat rendah" sebesar 0\% (0 siswa), "rendah" sebesar 25\% (5 siswa), "sedang" sebesar 55\% (11 siswa), "baik" sebesar 15\% (3 siswa), dan "sangat baik" sebesar 5\% (1 siswa).

sedangkan untuk posttest berada pada kategori "sangat rendah" sebesar 0\% (0 siswa), "rendah" sebesar 0\% (0 siswa), "sedang" sebesar $25 \%$ (5 siswa), "baik" sebesar $45 \%$ (9 siswa), dan "sangat baik" sebesar 30\% (6 siswa).

\section{PEMBAHASAN}

Berdasarkan pelaksanaan perlakuan latihan small sided games yang dilakukan secara sistematis, berulang-ulang, dan beban bertambah, serta menggunakan prinsip dan tahapan latihan yang sesuai prosedur tersebut, maka terbukti nyata bahwa latihan small sided-games memberi pengaruh yang signifikan terhadap akurasi passing siswa SSB Bina Taruna Tambakromo Pati.

Selanjutnya untuk hasil rata-rata pretest sebelum diberi perlakuan dengan metode latihan small sided games adalah sebesar 5,45, sedangkan nilai rata-rata setelah diberi perlakuan small sided games selama 14 kali pertemuan adalah 7,50.
Berdasarkan hasil tersebut, diperoleh selisih ratarata pretest dengan posttest sebesar 2,05. Dari selisih rata-rata tersebut dapat diketahui kenaikan persentase sebesar $38,61 \%$. Hal ini berarti bahwa hasil latihan small sided games terhadap akurasi passing siswa SSB Bina Taruna mempunyai pengaruh sebesar $38,61 \%$.embahasan difokuskan pada data hasil penelitian yang dikaitkan dengan permasalahan yang diangkat.

\section{SIMPULAN DAN REKOMENDAS}

Berdasarkan hasil penelitian yang telah diperoleh dengan analisis data dan pengujian hipotesis, maka dapat ditarik kesimpulan sebagai berikut: Ada pengaruh yang signifikan latihan small sided games terhadap akurasi passing pada siswa SSB Bina Taruna Tambakromo. Latihan small sided games mampu memberikan peningkatan akurasi passing siswa dengan peningkatan sebesar 2,05 atau meningkat.

Adapun rekomendasi yang diberikan berdasarkan penelitian ini yaitu: Bagi pihak SSB Bina Taruna dengan adanya penelitian ini diharapkan memahami dan mencermati setiap perkembangan akurasi passing khususnya dalam permainan sepak bola para siswa. Bagi pemain sepak bola SSB Bina Taruna yang sudah memiliki akurasi passing yang bagus agar ditingkatkan lagi

\section{REFERENSI}

Arikunto, S. (2010). Prosedur penelitian; suatu pendekatan praktik. (Edisi revisi). Jakarta: Rineka Cipta.

Herdiansyah, W., \& Nurasyifa, W. (2010). Mari Belajar Sepak Bola. Bogor: PT Regina Eka Utama

Karim, A. (2010). Pengaruh Latihan Small Sided Games Terhadap Peningkatan Ketepaatan Passing Dengan Kaki Bagian Dalam Pada Siswa Peserta Ekstrakurikuler Sepak Bola MTs Ali Maksum Bantul. Skripsi. Yogyakarta: UNY. 
Kusuma, I. A. (2015). Pengaruh Latihan Passing Berpasangan Terhadap Kemampuan Passing Bawah Siswa Sekolah Sepak Bola Kalasan Usia 10-12 Tahun. In Skripsi. Yogyakarta: UNY.

Rahmani, M. (2014). Buku Super Lengkap Olahraga. Jakarta Timur: Dunia Cerdas.

Scheunemann, T. (2008). Dasar-dasar sepak bola modern. Malang: Dioma.

Subagyo Irianto, dkk. (1995). Penyusunan Tes Keterampilan Bermain Sepakbola Bagi Siswa Sekolah Sepakbola PUSPOR IKIP Yogyakarta. Laporan Penelitian. Yogyakarta: FPOK Institut Keguruan dan Ilmu Pendidikan.

Sukardi. (2015). Evaluasi pendidikan. Jakarta: Bumi 